\title{
Forecasting of electricity demand in the region
}

\author{
Janusz Sowiński ${ }^{1, *}$ \\ ${ }^{1}$ Czestochowa University of Technology, Faculty of Electrical Engineering, 42-200 Częstochowa, \\ Poland
}

\begin{abstract}
Ongoing structural changes on the electricity market and technological development affecting consumers and producers increase uncertainty concerning demand for electricity, even in a short-time horizon. Because of this, it is necessary to develop forecasting methods. This paper presents a method for forecasting electricity demand based on the idea of an end-use model. Such models use regional electricity consumption rates and population growth predictions as input data, on the basis of which they yield electricity demand forecast for the whole country and for particular regions. The model also deploys stochastic differential equations for simulating time-variation of electricity consumption rates by means of the Euler method. On the basis of available statistical data, the results of a forecast in a medium-term horizon are presented.
\end{abstract}

\section{Introduction}

The structure of the power industry is extremely complex today, with a number of qualitatively different elements tied on many levels [11]. With respect to economic and technological criteria, it is possible to substitute one kind of fuel or energy by another at the stage of the final consumption. Owing to easy access to modern technologies and a wide supply of power devices and electrical appliances on the market, consumers can avail themselves of different forms and carriers of energy to fulfill their needs. When analyzing energy consumption in a region, it is therefore essential to take into account price relations among energy carriers, development in the technology of obtaining and transforming energy [2], as well as problems resulting from the increasing popularity of distributed electricity generation based on renewable energy sources. These factors, encumbered with high uncertainty, have impact on the future demand for energy. To fulfill that demand, power industry companies have to plan future investment, keeping in mind that insufficient infrastructure both in power plants and networks may significantly hamper development and progress in regional economy, leading to far-reaching consequences.

The market principles of regional economy, including power industry, call for specific functions to model energy balance. Classic analytical methods are no longer applicable, since forecasts have to include uncertainty and various forms of risk (cf. [3-5]). As proposed by Kendall, risk can be divided into categories according to its source, with the most important categories in the modeling of energy balance being operational risk

\footnotetext{
*Corresponding author: jansow@el.pcz.czest.pl
} 
(production risk, technological risk) and market risk (fuel price risk, regulation risk, environmental risk, financial and business risk, etc.).

Statistical report published by Główny Urząd Statystyczny (Statistics Poland, abbrev. GUS), concerning power use in Poland [6], comprises four main sectors of electricity consumption: industry, transport, agriculture and households, apart from other use. It also states basic energy consumption rates, such as total consumption per capita or industrial consumption per $1 \mathrm{~m}$. PLN of added value. These rates are indispensible for monitoring power consumption and managing it in a way ensuring sustained development $[7,8]$. The analysis of power consumption rates of various degrees of aggregation is also necessary for forecasting energy consumption by means of end-use type models [4, 5, 9-11, 16].

Variations of power consumption rates are dynamic processes with random perturbations. They can be modeled by means of stochastic differential equations [12].

\section{Statistical data}

The data published by GUS form Bank of Local Data [6]. They are grouped according to the division of the country into units and according to the category, such as natural resources and power industry. In the latter category, the data include total installed power capacity, power generated in plants, electricity generation from particular sources and electricity consumption in the sectors of economy.

Fig. 1 and Table 1 presents the population of the voivodeships in Poland. The subsequent analysis concerns total electricity consumption per capita in each voivodeship. Variation of electricity consumption rates per capita in the period 2001-2016 is presented in Fig.2 and in Table 2.

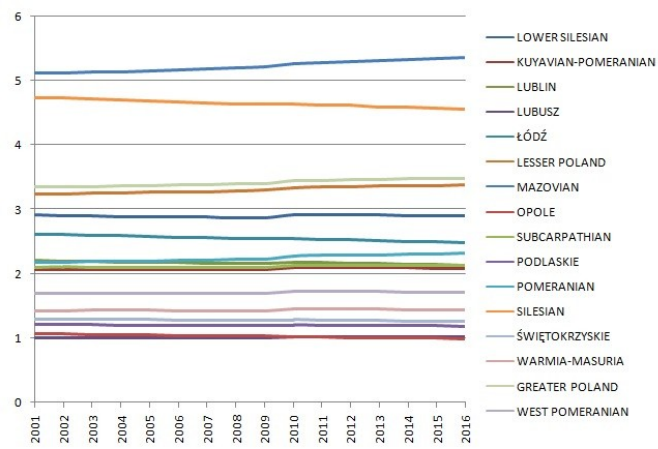

Fig.1. Population of Polish voivodeships in the period 2001-2016 in m. of people [6].

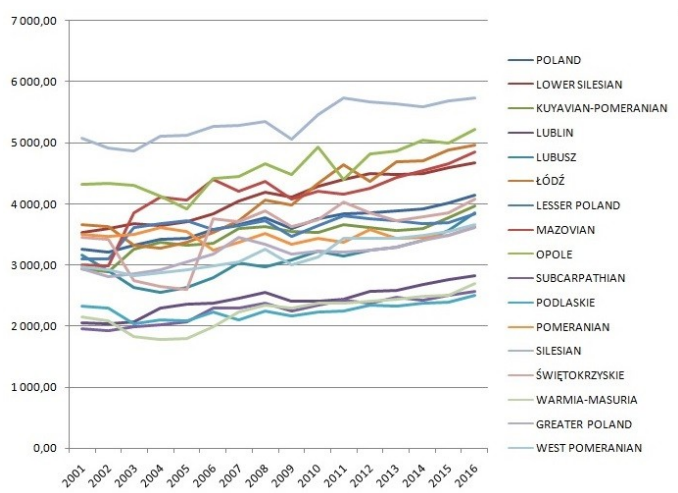

Fig. 2. Electricity consumption rates per capita in the period 2001-2016 in $\mathrm{kWh} /$ person [6]. 
Table 1. Population of Polish voivodeships in the period 2001-2016 in m. of people [6].

\begin{tabular}{|c|c|c|c|c|c|c|c|c|c|c|c|c|c|c|c|c|}
\hline \multirow{2}{*}{ Regions/voivodeships } & \multicolumn{16}{|c|}{ YEARS } \\
\hline & 2001 & 2002 & 2003 & 2004 & 2005 & 2006 & 2007 & 2008 & 2009 & 2010 & 2011 & 2012 & 2013 & 2014 & 2015 & 2016 \\
\hline POLAND & 38.242 & 38.219 & 38.191 & 38.174 & 38.157 & 38.125 & 38.116 & 38.136 & 38.167 & 38.530 & 38.538 & 38.533 & 38.496 & 38.479 & 38.437 & 38.433 \\
\hline LOWER SILESIAN & 2.910 & 2.905 & 2.898 & 2.893 & 2.888 & 2.882 & 2.878 & 2.877 & 2.877 & 2.917 & 2.917 & 2.914 & 2.910 & 2.908 & 2.904 & 2.904 \\
\hline KUYAVIAN-POMERANIAN & 2.070 & 2.069 & 2.068 & 2.068 & 2.068 & 2.066 & 2.066 & 2.068 & 2.069 & 2.099 & 2.098 & 2.096 & 2.093 & 2.090 & 2.086 & 2.084 \\
\hline LUBLIN & 2.202 & 2.197 & 2.191 & 2.185 & 2.180 & 2.173 & 2.166 & 2.162 & 2.157 & 2.179 & 2.172 & 2.166 & 2.156 & 2.148 & 2.140 & 2.133 \\
\hline LUBUSZ & 1.009 & 1.008 & 1.009 & 1.009 & 1.009 & 1.009 & 1.008 & 1.009 & 1.010 & 1.023 & 1.023 & 1.023 & 1.021 & 1.020 & 1.018 & 1.017 \\
\hline ŁÓDŹ & 2.617 & 2.607 & 2.597 & 2.588 & 2.577 & 2.566 & 2.556 & 2.549 & 2.542 & 2.542 & 2.534 & 2.525 & 2.513 & 2.504 & 2.494 & 2.485 \\
\hline LESSER PC & 3.236 & 3.237 & 3.253 & 3.260 & 3.266 & 3.271 & 3.279 & 3.287 & 3.298 & 3.337 & 3.347 & 3.354 & 3.361 & 3.368 & 3.373 & 3.382 \\
\hline MAZOVIAN & 5.122 & 5.129 & 5.136 & 5.146 & 5.158 & 5.172 & 5.188 & 5.204 & 5.222 & 5.267 & 5.286 & 5.302 & 5.317 & 5.335 & 5.349 & 5.366 \\
\hline OPOLE & 1.066 & 1.061 & 1.056 & 1.052 & 1.047 & 1.042 & 1.037 & 1.033 & 1.031 & 1.017 & 1.014 & 1.010 & 1.004 & 1.001 & 0.996 & 0.993 \\
\hline SUBCARPATHIAN & 2.104 & 2.105 & 2.097 & 2.098 & 2.098 & 2.098 & 2.097 & 2.099 & 2.102 & 2.128 & 2.129 & 2.130 & 2.129 & 2.129 & 2.128 & 2.128 \\
\hline PODLASKIE & 1.209 & 1.208 & 1.205 & 1.202 & 1.200 & 1.196 & 1.193 & 1.191 & 1.190 & 1.203 & 1.201 & 1.199 & 1.195 & 1.192 & 1.189 & 1.187 \\
\hline POMERANIAN & 2.178 & 2.184 & 2.189 & 2.194 & 2.199 & 2.204 & 2.211 & 2.220 & 2.230 & 2.275 & 2.284 & 2.290 & 2.296 & 2.302 & 2.308 & 2.316 \\
\hline SILESIAN & 4.742 & 4.732 & 4.715 & 4.701 & 4.686 & 4.669 & 4.654 & 4.646 & 4.641 & 4.635 & 4.626 & 4.616 & 4.599 & 4.586 & 4.571 & 4.559 \\
\hline ŚWIĘTOK & 1.299 & 1.296 & 1.292 & 1.289 & 1.285 & 1.280 & 1.276 & 1.273 & 1.270 & 1.283 & 1.278 & 1.274 & 1.268 & 1.263 & 1.257 & 1.253 \\
\hline WARMIA-MASURIA & 1.428 & 1.428 & 1.429 & 1.429 & 1.429 & 1.427 & 1.426 & 1.427 & 1.427 & 1.454 & 1.453 & 1.451 & 1.447 & 1.444 & 1.440 & 1.436 \\
\hline GREAT & 3.350 & 3.355 & 3.360 & 3.365 & 3.372 & 3.379 & 3.387 & 3.398 & 3.408 & 3.447 & 3.455 & 3.462 & 3.467 & 3.473 & 3.475 & 3.482 \\
\hline WEST POMERANIAN & 1.698 & 1.698 & 1.696 & 1.695 & 1.694 & 1.693 & 1.692 & 1.693 & 1.693 & 1.724 & 1.723 & 1.721 & 1.719 & 1.715 & 1.710 & 1.708 \\
\hline
\end{tabular}

Table 2. Electricity consumption rates per capita in the period 2001-2016 in kWh/person [6].

\begin{tabular}{|c|c|c|c|c|c|c|c|c|c|c|c|c|c|c|c|c|}
\hline \multirow{2}{*}{ Region/voivodeship } & \multicolumn{16}{|c|}{ YEARS } \\
\hline & 2001 & 2002 & 2003 & 2004 & 2005 & 2006 & 2007 & 2008 & 2009 & 2010 & 2011 & 2012 & 2013 & 2014 & 2015 & 2016 \\
\hline POLAND & 3261 & 3209 & 3326 & 3417 & 3438 & 3586 & 3662 & 3768 & 3589 & 3749 & 3832 & 3852 & 3891 & 3924 & 4009 & 4141 \\
\hline LOWER SILESIAN & 3536 & 3592 & 3677 & 3650 & 3711 & 3833 & 4056 & 4191 & 4111 & 4291 & 4402 & 4500 & 4481 & 4497 & 4594 & 4676 \\
\hline KUYAVIAN-POMERANIAN & 2937 & 2885 & 3247 & 3368 & 3312 & 3345 & 3600 & 3622 & 3546 & 3526 & 3664 & 3615 & 3565 & 3600 & 3769 & 3964 \\
\hline LUBLIN & 2050 & 2032 & 2065 & 2289 & 2350 & 2375 & 2444 & 2544 & 2398 & 2396 & 2436 & 2561 & 2587 & 2683 & 2758 & 2822 \\
\hline LUBUSZ & 3159 & 2904 & 2630 & 2548 & 2624 & 2781 & 3028 & 2960 & 3076 & 3216 & 3142 & 3242 & 3279 & 3397 & 3552 & 3847 \\
\hline ŁÓDŹ & 3661 & 3632 & 3325 & 3279 & 3381 & 3539 & 3727 & 4067 & 3990 & 4332 & 4638 & 4371 & 4693 & 4705 & 4885 & 4959 \\
\hline LESSER POLAND & 3110 & 3103 & 3612 & 3690 & 3725 & 3582 & 3654 & 3727 & 3470 & 3652 & 3810 & 3769 & 3735 & 3680 & 3693 & 3846 \\
\hline MAZOVIAN & 3002 & 2986 & 3857 & 4112 & 4075 & 4401 & 4210 & 4378 & 4085 & 4219 & 4165 & 4256 & 4442 & 4545 & 4662 & 4859 \\
\hline OPOLE & 4328 & 4345 & 4310 & 4134 & 3926 & 4416 & 4452 & 4654 & 4479 & 4942 & 4405 & 4819 & 4870 & 5040 & 5003 & 5222 \\
\hline SUBCARPATHIAN & 1954 & 1925 & 1984 & 2030 & 2075 & 2294 & 2301 & 2380 & 2253 & 2350 & 2416 & 2380 & 2480 & 2415 & 2497 & 2568 \\
\hline PODLASKIE & 2323 & 2288 & 2040 & 2102 & 2094 & 2236 & 2110 & 2246 & 2166 & 2229 & 2239 & 2338 & 2318 & 2368 & 2390 & 2495 \\
\hline POMERANIAN & 3500 & 3474 & 3505 & 3615 & 3559 & 3245 & 3380 & 3522 & 3337 & 3439 & 3376 & 3584 & 3443 & 3460 & 3488 & 3635 \\
\hline SILESIAN & 5070 & 4907 & 4861 & 5098 & 5125 & 5261 & 5277 & 5337 & 5054 & 5453 & 5730 & 5661 & 5639 & 5580 & 5681 & 5723 \\
\hline ŚWIĘTOKRZYSKIE & 3465 & 3426 & 2746 & 2645 & 2604 & 3769 & 3718 & 3888 & 3627 & 3742 & 4029 & 3859 & 3732 & 3790 & 3863 & 4086 \\
\hline WARMIA-MASURIA & 2148 & 2094 & 1825 & 1780 & 1800 & 1995 & 2239 & 2345 & 2300 & 2380 & 2384 & 2416 & 2446 & 2483 & 2514 & 2701 \\
\hline GREATER POLAND & 2927 & 2805 & 2848 & 2918 & 3044 & 3180 & 3455 & 3346 & 3180 & 3231 & 3209 & 3239 & 3299 & 3402 & 3480 & 3616 \\
\hline WEST POMERANIAN & 2959 & 2923 & 2818 & 2867 & 2921 & 2974 & 3037 & 3255 & 3000 & 3133 & 3429 & 3430 & 3438 & 3481 & 3542 & 3660 \\
\hline
\end{tabular}




\section{End-use type of model for forecasting electricity demand}

The underlying idea of an end-use type model is that demand for electricity is proportional to the electricity consumption rate and the value of the input variable. The main role of this model is to tie demand for electricity with the structural changes occurring in the economy.

An end-use model analyses demand for electricity at the level of an end user, where the notion of end user can be defined at various tiers of the hierarchy. Thus, depending on the level of disaggregation of economy, an end user can be a sector of economy, a branch of industry, a specific technology or an individual. On the one hand, the model can be easily modified and expanded, and on the other, it is possible to introduce into it a number of assumptions on the structure and electricity consumption variation of the end user. The degree of detail in the model depends on its intended application - whether it is going to be a long-term forecasting tool, or a short-term analysis tool, and on the availability of statistical data that have to be supplied.

The electricity demand forecasting model requires constructing a scenario for the input quantity, i.e. population change. This can be done on the basis of external models or heuristic analysis. Another key task in creating an end-use model is forecasting the electricity consumption rates per capita in the forecast horizon.

\section{Models of dynamic processes}

A number of dynamic processes with random perturbations in economics and in power industry can be modeled by means of stochastic equations of Ito type [13]. It is a powerful tool for analyzing real phenomena, so in this study it has been used for modeling electricity demand.

Applying the Euler method [12] for solving stochastic differential equations makes it possible to simulate the behavior of electricity consumption rates in the future. The stochastic process of a number of continuous variables can be described by means of stochastic differential equations (SDE) of the following general form:

$$
d X_{t}=F\left(t, X_{t}\right) d t+G\left(t, X_{t}\right) d W_{t}
$$

where: $X$ - state variable, $W$ - Wiener process variable (Brownian motion), $F$ - function determining the trend, $G$ - diffusion function.

On the basis of Eq. (1) a number of special versions of the model can be defined. The simplest one is a linear model of the trend with a random Brownian motion (BM) component, containing two terms: a deterministic term and a random term:

$$
d X_{t}=A(t) d t+V(t) d W_{t}
$$

A variant of this model is the one of relative variation of the state variable with a random component following geometric Brownian motion (GBM):

$$
d X_{t}=B(t) X_{t} d t+V(t) X_{t} d W_{t}
$$

The variation of the random component can be also modeled as constant elasticity of variance $(\mathrm{CEV})$ :

$$
d X_{t}=B(t) X_{t} d t+V(t) X_{t}^{\alpha(t)} d W_{t}
$$

The fundamental property of this model is the possibility of finding a dependence between the state variable and its variation through the value of the exponent $\alpha(t)$. 
Another variant of model (1) is SDE from Mean-Reverting Drift SDEMRD:

$$
d X_{t}=S(t)\left[L(t)-X_{t}\right] d t+D\left(t, X_{t}^{\alpha(t)}\right) V(t) d W_{t}
$$

where: $S(t)$ - drift reverting rate, $L(t)$ - drift reverting level.

If the function $D\left(t, X_{t}^{\alpha(t)}\right)=1$ in Eq. 5, then this formula can be transformed into the variant known as Hull-White/Vasicek (HWV) model:

$$
d X_{t}=S(t)\left[L(t)-X_{t}\right] d t+V(t) d W_{t}
$$

The simulation of electricity consumption rates, assumed to be state variables $X_{t}$ involves obtaining numerical solutions to stochastic differential equations. The equations will be solved by means of the Euler method.

\section{Simulation of electricity consumption rates described by SDE}

Modeling the SDE describing time-variation of electricity consumption rates per capita in a region [13], approximating the solutions by the Euler method and the analysis were carried out by programming own scripts utilizing tools available in the libraries of the package Matlab by MathWorks and in the calculation sheet Excel by Microsoft.

The analysis involved the following variants of SDE models, in which the state variable corresponds to yearly relative increases of electricity consumption rates per capita in a region:

- the GBMC model (taking into account correlation between electricity consumption rates in Wiener processes)

$$
d X_{t}=\mu X_{t} d t+\sigma X_{t} d W_{t}
$$

- the CEV model

$$
d X_{t}=\mu X_{t} d t+\sigma X_{t}^{\frac{1}{2}} d W_{t}
$$

- the SDEMRD model

$$
d X_{t}=0.02\left(\mu-X_{t}\right) d t+\sigma X_{t}^{\frac{1}{2}} d W_{t}
$$

- the HWV model

$$
d X_{t}=0.02\left(\mu-X_{t}\right) d t+\sigma d W_{t}
$$

where: $\mu$ - mean value of the variable $X_{t}, \sigma$-standard deviation of the variable $X_{t}$.

In the models described by Equations (7) $\div(10)$ two parameters were estimated for the electricity consumption rate per capita in a region, namely the mean value and the standard deviation of the relative increases per year. The values of the exponent $\alpha=0.5$ and the value of the drift-reverting rate $S(t)=0.02$ were stipulated. The measure of risk in all the abovepresented model is the value of the standard deviation $\sigma$. The results of the simulation of electricity demand rates per capita in a region are presented in Fig. 3.

The models GBMC and CEV adequately describe phenomena following stock exchange rules, whereas the models SDEMRD and HWV are suitable for describing processes following market principles. The selection of a model for representing a specific electricity demand rate should be therefore motivated by the assumptions adopted in the scenario constructed for an end-use model. The pairs of models GBMC - CEV and 
SDEMRD - HWV yield similar results of the simulation, which could be expected after analyzing the mathematical formulas $(7) \div(10)$ describing these models.
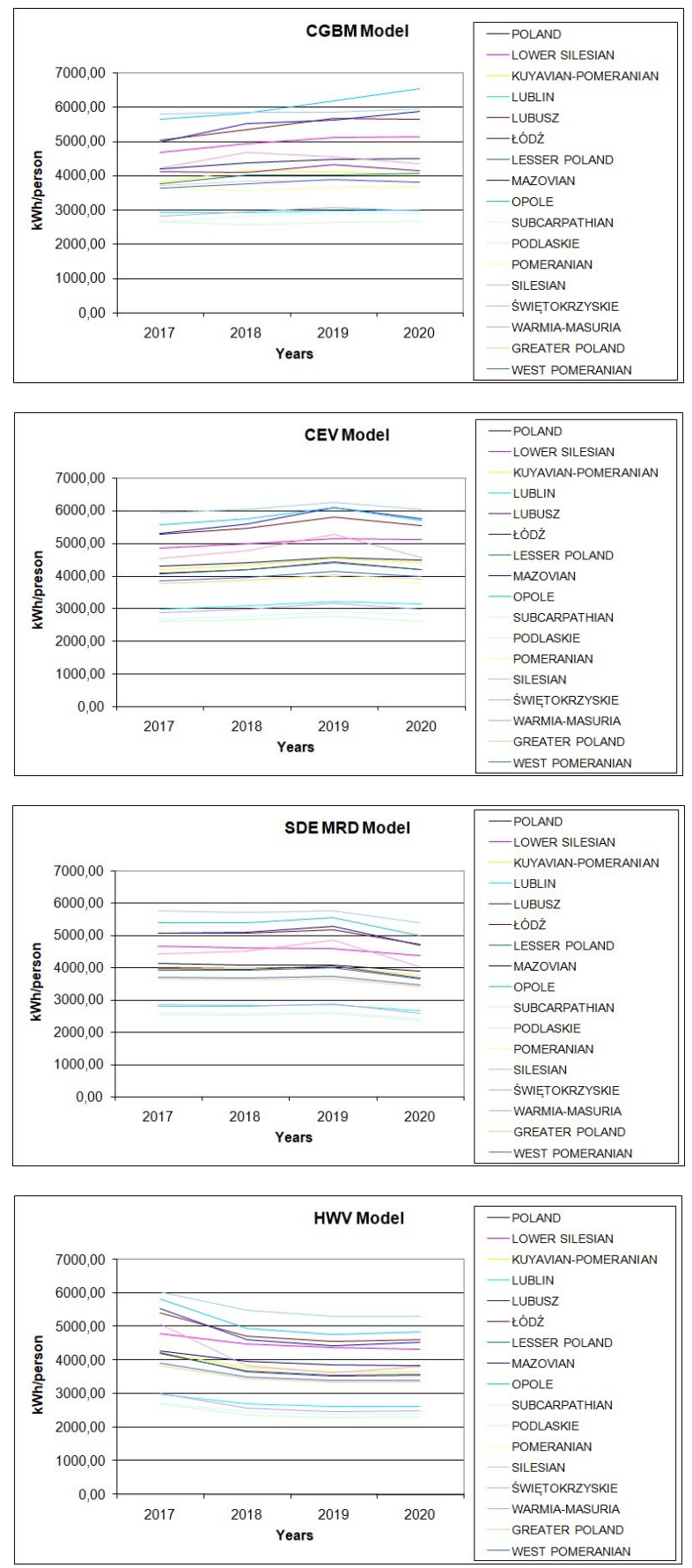

Fig.3. Simulations of electricity demand rates per capita in regions obtained by employing four SDE models. 
Each of the models contains a deterministic term, representing the trend of the variable, and a random term, in which the standard deviation of the variable is a measure of uncertainty. Uncertainty is understood here in the economic sense, whereas in the mathematical sense it would be a measure of risk, since the probability distribution of the variable is known.

\section{Simulations of electricity demand in regions}

Simulations of total demand for electricity in the regions obtained on the basis of electricity demand rates require scenarios for population change in the time period constituting the forecast horizon. To this end, a GUS population projection for the regions was used (Table $3)$.

The simulation results obtained on the basis of the models GBMC and CEV (following the stock-exchange principles) are similar. The same is true of the results obtained on the basis of the models SDEMRD and HWV (following the market principles). This is due to the similarity between the two pairs of models: GBMC and CEV vs. SDEMRD and HWV, which differ within each pair only by the form of the random term. Since the value of standard deviation was estimated on the basis of previous variations of the electricity consumption rates, the level of risk was assumed to be the same as in the past. Assuming a higher value of standard deviation would result in a higher risk level. This problem is discussed in detail in [13].

Table 3. Population projection for Poland and the voivodeships for the period 2017-2020 [6].

\begin{tabular}{|l|c|c|c|c|}
\hline \multirow{2}{*}{ Region/voivodeship } & \multicolumn{5}{|c|}{ Population projection in m. of individuals } \\
\cline { 2 - 5 } & 2017 & 2018 & 2019 & 2020 \\
\hline POLAND & 38.315 & 38.260 & 38.201 & 38.138 \\
\hline LOWER SILESIAN & 2.887 & 2.880 & 2.873 & 2.867 \\
\hline KUYAVIAN-POMERANIAN & 2.078 & 2.074 & 2.070 & 2.065 \\
\hline LUBLIN & 2.123 & 2.114 & 2.105 & 2.096 \\
\hline LUBUSZ & 1.016 & 1.014 & 1.012 & 1.010 \\
\hline ŁÓDŹ & 2.468 & 2.457 & 2.446 & 2.434 \\
\hline LESSER POLAND & 3.383 & 3.388 & 3.392 & 3.396 \\
\hline MAZOVIAN & 5.361 & 5.371 & 5.380 & 5.388 \\
\hline OPOLE & 0.984 & 0.978 & 0.972 & 0.967 \\
\hline SUBCARPATHIAN & 2.123 & 2.120 & 2.118 & 2.115 \\
\hline PODLASKIE & 1.180 & 1.176 & 1.172 & 1.168 \\
\hline POMERANIAN & 2.313 & 2.317 & 2.321 & 2.324 \\
\hline SILESIAN & 4.534 & 4.516 & 4.497 & 4.478 \\
\hline SWIETTOKRZYSKIE & 1.244 & 1.238 & 1.232 & 1.226 \\
\hline WARMIA-MASURIA & 1.433 & 1.429 & 1.425 & 1.421 \\
\hline GREATER POLAND & 3.483 & 3.486 & 3.488 & 3.490 \\
\hline WEST POMERANIAN & 1.705 & 1.701 & 1.697 & 1.692 \\
\hline
\end{tabular}

Examples of electricity demand simulations are presented in Tables 4 and 5. The forecasts obtained from the models CGBM and CEV can be considered as scenarios of trend continuation, whereas the models SDEMRD and HWV predict decrease in electricity demand caused by diminishing power consumption mainly owing to technological progress. 
Table 4. Electricity demand forecast for Poland for the years 2017-2020 in TWh.

\begin{tabular}{|c|c|c|c|c|}
\hline \multirow{2}{*}{ Year } & \multicolumn{4}{|c|}{ Model } \\
\cline { 2 - 5 } & CGBM & CEV & SDE MRD & HWV \\
\hline 2017 & 161 & 164 & 159 & 164 \\
\hline 2018 & 168 & 168 & 157 & 152 \\
\hline 2019 & 171 & 174 & 156 & 147 \\
\hline 2020 & 172 & 171 & 148 & 146 \\
\hline
\end{tabular}

Table 5. Electricity demand forecast for one region (Silesia) for the years 2017-2020 in GWh.

\begin{tabular}{|c|c|c|c|c|}
\hline \multirow{2}{*}{ Year } & \multicolumn{4}{|c|}{ Model } \\
\cline { 2 - 5 } & CGBM & CEV & SDE MRD & HWV \\
\hline 2017 & 26289.7 & 26863.9 & 26139.5 & 27302.0 \\
\hline 2018 & 26382.3 & 27259.9 & 25801.8 & 24701.8 \\
\hline 2019 & 26303.6 & 28087.6 & 25887.0 & 23874.1 \\
\hline 2020 & 26567.6 & 27002.6 & 24121.7 & 23727.9 \\
\hline
\end{tabular}

\section{Concluding remarks}

Electricity demand in the regions and in the whole country effectively depends on electricity consumption rates, since population projection displays little variation.

The simulations of electricity consumption rates carried out for the horizon up to 2020 yield different results depending on the model assumed. The results obtained on the basis of each model can be treated as a scenario for the electricity consumption rate behavior in the future. The simulations presented here illustrate the use of various SDE models describing electricity consumption rates and of the end-use methodology for determining electricity demand. These tools provide useful support for the process of developing energy balance since they allow for experts' assessments concerning population projections and verifications of the models' coefficients. It should be taken into account that the development of power generation has to be correlated with the development of the power grid [14], and to actions ensuring the safety of its operation [15].

As this study indicates, the Euler method is adequate for carrying out simulations of stochastic variables described by differential equations, taking into account the uncertainty of processes occurring in power industry, resulting from the impact of the external environment on the models.

\section{References}

[1] J. Sowiński, "End-use"-model prognozy zapotrzebowania bezpośredniego na energię. in: Dobrzańska I. (ed). Prognozowanie w elektroenergetyce. Zagadnienia wybrane (WPCz, Częstochowa, 2002)

[2] I. Pavlova-Marciniak, Przegląd Elektrotechniczny 3, 216-219 (2009)

[3] G. Dudek, Electric Power Systems Research vol.80 (4), 465-472 (2010)

[4] G.R. Newsham, C.L. Donnelly, Energy Policy 59, 133-142 (2013) 
[5] L.G. Swan, I.V. Ugursal, Renewable and Sustainable Energy Reviews. 13 (8), 18191835 (2009)

[6] www.stat.gov.pl (16.09.2018) GUS

[7] K. Billewicz, An alternative view at energy efficiency, Rynek Energii 105 (2), (2013)

[8] W. Jędral, Efektywność energetyczna jako ważny zasób energetyczny - porównanie z wybranymi źródłami energii, Rynek Energii 95 (4), (2011)

[9] B. Chateau, B. Lapillonne, Energy Policy 6 (2), 140-157 (1979)

[10] Commission of European Communities, The MIDAS Energy Model (EC, Bruxelles, 1985)

[11] International Atomic Energy Agency (IAEA). Model for Analysis of the Energy Demand (MAED) (IAEA, Vienna, 1986)

[12] B.K. Øksendal, Stochastic Differential Equations: An Introduction with Applications (Springer, Berlin, 2003)

[13] J. Sowiński, Inwestowanie w źródła wytwarzania energii elektrycznej $w$ warunkach rynkowych (WPCz, Częstochowa, 2008)

[14] M. Kornatka, A. Gawlak, Comparative analysis of operating conditions in Polish medium-voltage and $110 \mathrm{kV}$ networks, Proceedings of The $8^{\text {th }}$ International Scientific Symposium ELEKTROENERGETIKA 2015, Stara Lesna, Slovak Republic (2015)

[15] M. Kornatka, The weighted kernel density estimation methods for analysing reliability of electricity supply, in: 17th International Scientific Conference on Electric Power Engineering (EPE), Prague (2016) 